\title{
Ridge Preservation using Dermis Allograft Tissue Matrix Membrane vs Connective Tissue Graft
}

\author{
${ }^{1}$ Elizabeth Meyers Tomlin, ${ }^{2}$ David G Kerns, ${ }^{3}$ Jeffrey A Rossmann, ${ }^{4}$ M Miles Beach, ${ }^{5}$ Ibtisam Al-Hashimi \\ ${ }^{6}$ Celeste M Abraham, ${ }^{7}$ Eric S Solomon, ${ }^{8}$ Harvey P Kessler
}

\begin{abstract}
Purpose: The purpose of this study was to compare extraction socket healing and alveolar ridge preservation using autogenous bone covered with connective tissue graft (CT) or acellular dermal matrix (ADM).

Materials and methods: Sixteen nonsmoking, healthy patients with 18 nonmolar teeth requiring extraction participated in the study. Following extraction, the sockets were debrided, measured, and grafted with autogenous bone, then covered with either CT or ADM. Measurements of alveolar ridge width and height were made at baseline and after 16 to 20 weeks post extraction. Soft and hard tissue biopsies of the extraction sites were evaluated histomorphometrically.
\end{abstract}

Results: The mean buccolingual ridge width loss was $0.19 \mathrm{~mm}$ for both CT and ADM groups. The mean vertical bone gain was $1.08 \mathrm{~mm}$ bone for the CT group and $0.82 \mathrm{~mm}$ for the ADM group. Histologic evaluation revealed a mean bone fill of 40.67 and $50.76 \%$ for CT and ADM group respectively. Student t-tests did not reveal significant difference between the two groups.

Conclusion: The overall results of the study suggest that the use of bone graft covered with either CT or ADM is useful for ridge preservation.

Keywords: Ridge preservation, Membranes, Socket, Tooth extraction, Implant, Guided bone regeneration (GBR).

How to cite this article: Tomlin EM, Kerns DG, Rossmann JA, Beach MM, Al-Hashimi I, Abraham CM, Solomon ES, Kessler HP. Ridge Preservation using Dermis Allograft Tissue Matrix Membrane vs Connective Tissue Graft. J Contemp Dent 2014;4(1):10-16.

Source of support: Nil

Conflict of interest: None

${ }^{1}$ Graduate, ${ }^{2,3,5,8}$ Professor, ${ }^{4}$ Associate Professor

${ }^{6}$ Assistant Professor, ${ }^{7}$ Executive Director

${ }^{1}$ Private Practice of Periodontics, Dallas, Texas, USA

${ }^{2}$ Director of Graduate Periodontics, Baylor College of Dentistry Dallas, Texas, USA

${ }^{3-6}$ Department of Periodontics, Baylor College of Dentistry Dallas, Texas, USA

${ }^{7}$ Department of Administration, Baylor College of Dentistry, Dallas Texas, USA

${ }^{8}$ Department of Oral Pathology, Baylor College of Dentistry, Dallas Texas, USA

Corresponding Author: David G Kerns, Professor and Director of Graduate Periodontics, Baylor College of Dentistry, Dallas, Texas, USA, Phone: 214-828-8140, e-mail: dkerns@bcd.tamhsc.edu

\section{INTRODUCTION}

The quality and quantity of bone is essential for successful of dental implant placement. ${ }^{1-3}$ Studies have shown that placing autogenous bone graft in the extraction socket and covering it with occlusive membrane helps preserve the alveolar ridge by allowing osteogenic cell populations to inhabit the osseous wound. ${ }^{4-6}$

A number of barrier membranes are already being used in clinical practice including acellular dermal matrix AlloDerm ${ }^{\circledR}$ (ADM), which has proven to preserve significantly greater ridge thickness. ${ }^{7}$ The ADM allograft acts as a scaffold for the vascular endothelial cells to travel from the adjacent tissue margins. ${ }^{8}$ Puros ${ }^{\circledR}$ Dermis Allograft Tissue Matrix is an ADM with natural collagen matrix and mechanical properties of native dermis. ${ }^{9-11}$ Although both types of membrane have proven useful for ridge preservation, However, there is a lack in studies that compares the effectiveness of Puros ${ }^{\circledR}$ Dermis allograft tissue matrix (ADM) $v s$ connective tissue membrane $(\mathrm{CT})$ in ridge preservation. Therefore, the purpose of this study was to compare the healing of extraction sockets grafted with autogenous bone and covered with Puros ${ }^{\mathbb{R}}$ Dermis allograft tissue matrix (ADM) or connective tissue membrane $(\mathrm{CT})$ in ridge preservation procedures.

\section{MATERIALS AND METHODS}

Sixteen patients underwent a screening process and consented for clinical trial participation in this study. All subjects in the study were recruited from the patient pool at the Baylor College of Dentistry, Texas A\&M University System Health Science Center between July 2008 and June 2009. Inclusion criteria for patients were: age $\geq 18$ years old, good systemic health, having a nonmolar tooth (bordered by at least one tooth on either side to insure a well-seated stent for clinical measurements) in need of extraction prior to implant placement and restoration. All patients signed an informed consent to clinical research approved by the Institutional Review Board at Baylor College of Dentistry. Exclusion criteria were: smoking; pregnant or lactating female patients; significant systemic disease (such as uncontrolled diabetes, osteoporosis or autoimmune diseases precluding surgical procedures); uncontrolled periodontal disease and/or patients unwilling to undergo treatment; poor compliance and poor oral hygiene; an allergy to any material 
or medication used in the grafting procedures; previous head and neck radiation; chemotherapy within the past 12 months; requirement for antibiotic prophylaxis for heart defects.

\section{SURGICAL PROCEDURES}

A single operator (EMT) performed all surgical procedures. The surgical sites were anesthetized with $2 \%$ lidocaine $\mathrm{HCl}, 1: 100,000$ epinephrine followed by $0.5 \%$ bupivacaine, 1:200,000 epinephrine. Intrasulcular incisions extended at least one tooth mesial and one tooth distal from the tooth to be extracted on the buccal and lingual aspects. Full thickness buccal flaps were reflected to the mucogingival junction on each patient. A full thickness lingual flap was reflected approximately $6 \mathrm{~mm}$ beyond the crest in order to secure each membrane underneath the lingual flap. The full thickness flap was extended to a continuous partial thickness flap, if needed to aid in wound closure.

Concerted efforts were made to minimize trauma during the extractions. Each socket was debrided and irrigated with sterile $0.9 \% \mathrm{NaCl}$ saline solution. Data were recorded again, prior to grafting, using the same University of North Carolina (UNC) probe and the custom made measuring stent of each patient. Baseline clinical horizontal and vertical measurements of the alveolar ridge were collected prior to extraction using a periodontal probe (CP 15 UNC, Hu-Friedy, Chicago, IL) to the nearest $0.5 \mathrm{~mm}$. Measurements also were obtained using a stent immediately after tooth extraction. Horizontal measurements of the ridge width mesiodistally (M-D) and buccolingually (B-L), also the thickness of facial and lingual walls of the extraction socket were obtained using a caliper and probe mid-crestal, $3 \mathrm{~mm}$ apical to the bone crest. Vertical measurements were obtained through predrilled holes in the coronal portion of the stent at the tooth line angles, mesial-buccal, mesiolingual, distobuccal, and distolingual the bone crest (Fig. 1). The holes in the stent

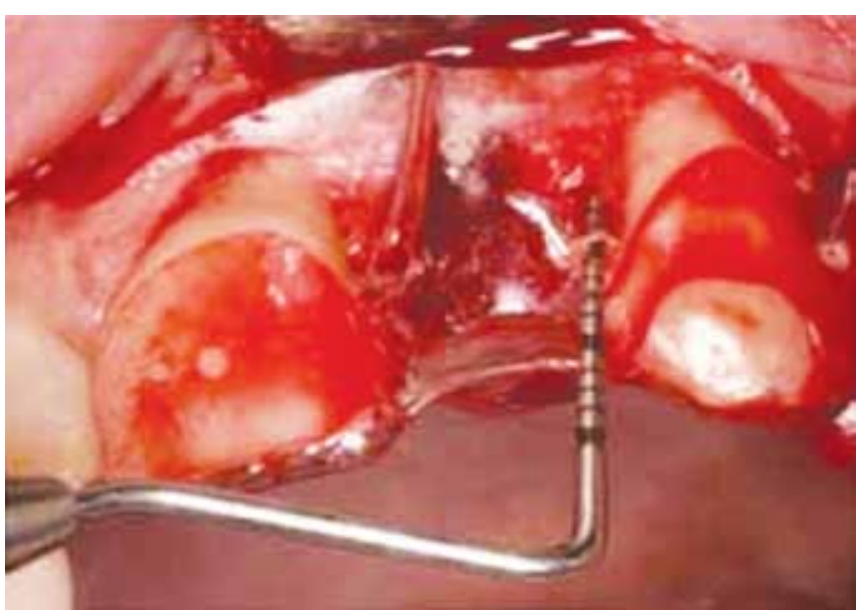

Fig. 1: Stent placed on the occlusal surfaces of the adjacent teeth. UNC probe is placed through one of the predrilled holes, measuring the vertical height of the bone in relation to the stent were used in an attempt to standardize the measurements. Similar horizontal and vertical measurements of the alveolus were repeated prior to placement of the implant.

The extraction socket was filled with autogenous bone collected using an osseous collection device (Safescraper; Biomet 3i, Palm Beach Gardens, FL) from adjacent separate oral sites. Light pressure was used on the autogenous bone graft particles to prevent over-compaction. The socket was filled to the height of the mesial and distal extraction socket bone walls. The barrier membrane (CT or Puros Dermis ${ }^{\circledR}$ ) was trimmed to the shape and size of the extraction socket plus at least $3 \mathrm{~mm}$ overlap and passively placed over the bone graft. If $\mathrm{CT}$ was used, it was harvested from the patient's palate or maxillary tuberosity area. Each membrane was retained using 4-0 chromic gut, resorbable suture and 4-0 polyglactin 910 sutures (Vicryl, Ethicon, Cornelia, GA), in a cross-mattress and interrupted-loop style (Figs 2 and 3$){ }^{4}$

Antibiotic was prescribed for each patient; Amoxicillin (500 mg, tid, for 7 days), or clindamycin (300 mg, qid for 7 days) for those allergic to amoxicillin. The antibiotic regimen started one day prior to the surgery. Ibuprofen, $600 \mathrm{mg}, 3$ to 4 times a day was prescribed and recommended for aid in control of postoperative discomfort (narcotics were supplemented if needed). Patient postoperative instructions included avoidance of mechanical cleaning of the surgical area (s) for 1 week following the surgery and $0.12 \%$ chlorhexidine rinse twice a day for 3 weeks.

Postsurgical appointments were scheduled at 1, 3,6 and 8 weeks after surgery. Supragingival plaque removal, oral hygiene reinforcement, and health history updates were performed at each postsurgical visit by the operator. Sutures were removed at 3 weeks.

After a healing period of 16 to 18 post extraction, the sites were re-entered for placement of an implant. A $4 \mathrm{~mm}$ punch biopsy was obtained from soft-tissues for histological evaluation at the extraction site prior to full-thickness flap reflection. Clinical measurements using each patient's stent were made for the width and height of the crest of alveolar bone after flap reflection. A trephine with an internal diameter of $2.75 \mathrm{~mm}$ was used to procure a $6 \mathrm{~mm}$-long bone core specimen from the implant osteotomy site. Each bone core was obtained using abundant irrigation at the implant osteotomy site. Both biopsies specimens were placed in 10\% neutral buffered formalin for histological analysis.

Following implant placement (Figs 4A to F), the flaps were sutured with 4-0 chromic gut sutures. The patients were instructed to follow the same postoperative regimen as the first surgical procedure.

\section{Histologic Processing and Histomorphometry}

Bone core biopsy specimens were placed in decalcifying solution (a combination of hydrochloric acid and butanedioic 
acid) until they could be hemisected easily using only a sharp scalpel blade. Once adequately decalcified, the bone core was dehydrated with a graded series of alcohols (increasing concentration of 70 to $100 \%$ ethanol baths). After dehydration, the specimen was immersed in hot paraffin under pressure, replacing the ethanol, and the specimens were embedded in paraffin for sectioning on a standard microtome at 4 to 6 microns. The slides were stained with hematoxylin and eosin and prepared for histologic analysis with the light microscope. Soft tissue specimens were processed in the same manner, except for decalcification.

All cores were digitized at the same magnification $(\times 5)$ using a microscope and digital camera. The images were converted into a JPEG digital image using image capture software (Olympus ${ }^{\circledR}$ BX-41, Olympus America, Center Valley, PA, USA). Histomorphometric measurements were completed using an image analysis software program (NIS Elements ${ }^{\circledR}$, Nikon Instruments Inc., Melville, NY, USA). One slide made from the center slice of each core was evaluated for the percentage of new bone formation (vital bone). All histomorphometric analysis was done without knowledge of the treatment assignment of the sections. The bone fill for the entire core was measured by outlining each individual segment of vital bone, yielding a percentage of bone fill.

Additional soft tissue samples were stained with Verhoeff's elastin stain. The Verhoeff's elastin stain was
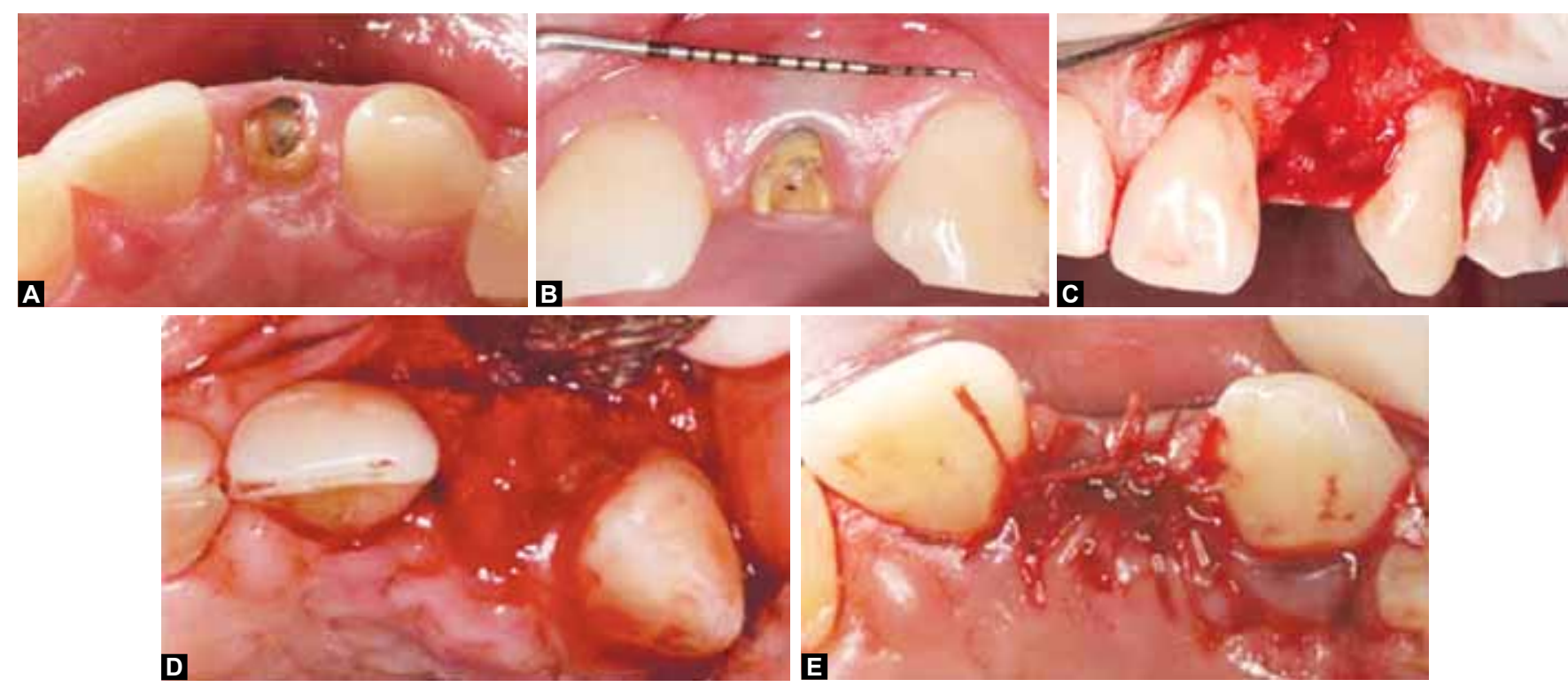

Figs $2 \mathrm{~A}$ to $\mathrm{E}$ : $\mathrm{CT}$ is used as a membrane: (A) occlusal view of nonrestorable tooth, (B) buccal view of nonrestorable tooth, (C) buccal dehiscence present in the thin buccal plate, (D) autogenous bone placed in the socket, and (E) CT placed as membrane and flap closed to primary closure
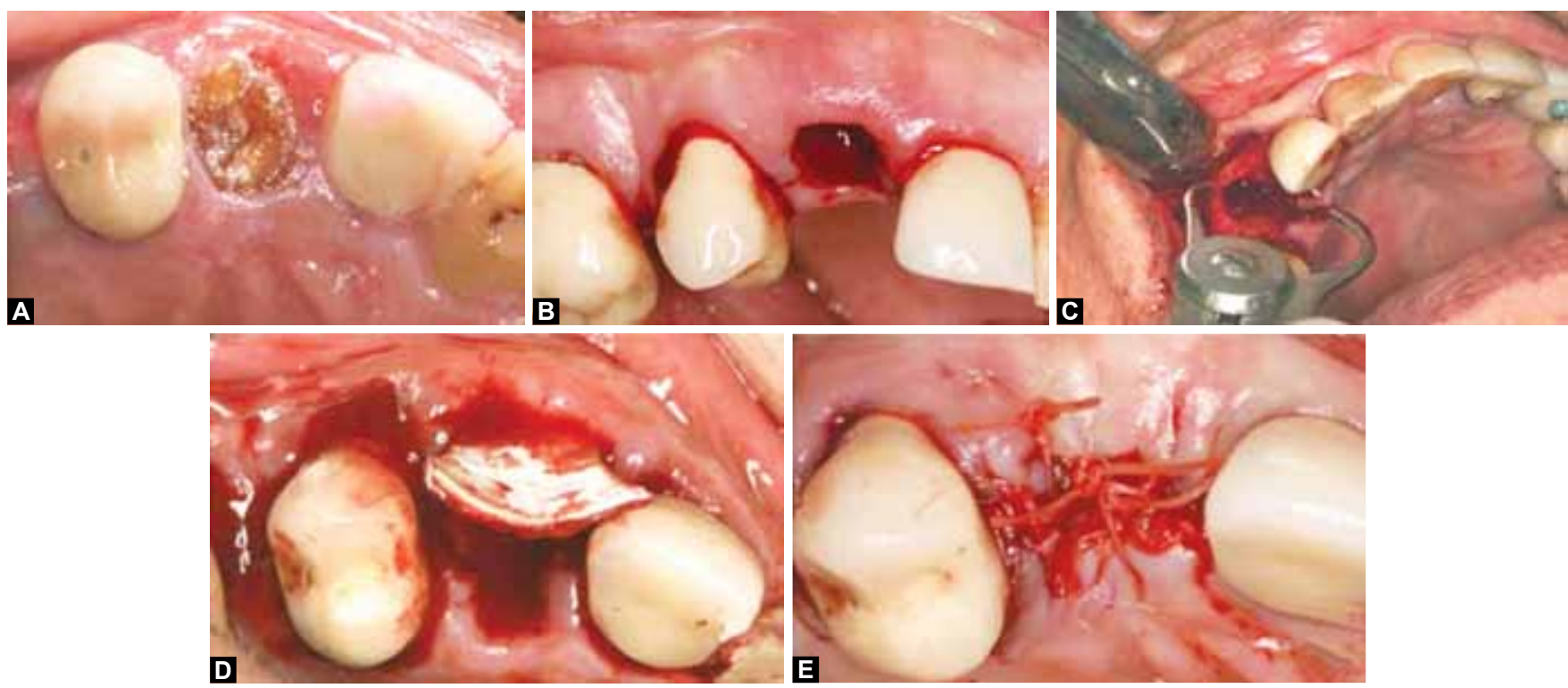

Figs $3 A$ to $E$ : ADM is used as a membrane: $(A)$ occlusal view of the nonrestorable tooth, $(B)$ buccal view of ridge after extraction of tooth, (C) clinician measuring the buccal-lingual width of the ridge with calipers, (D) initial placement of ADM to be used as a membrane over the socket filled with autogenous bone, and $(E)$ buccal and lingual flaps closed to primary closure 


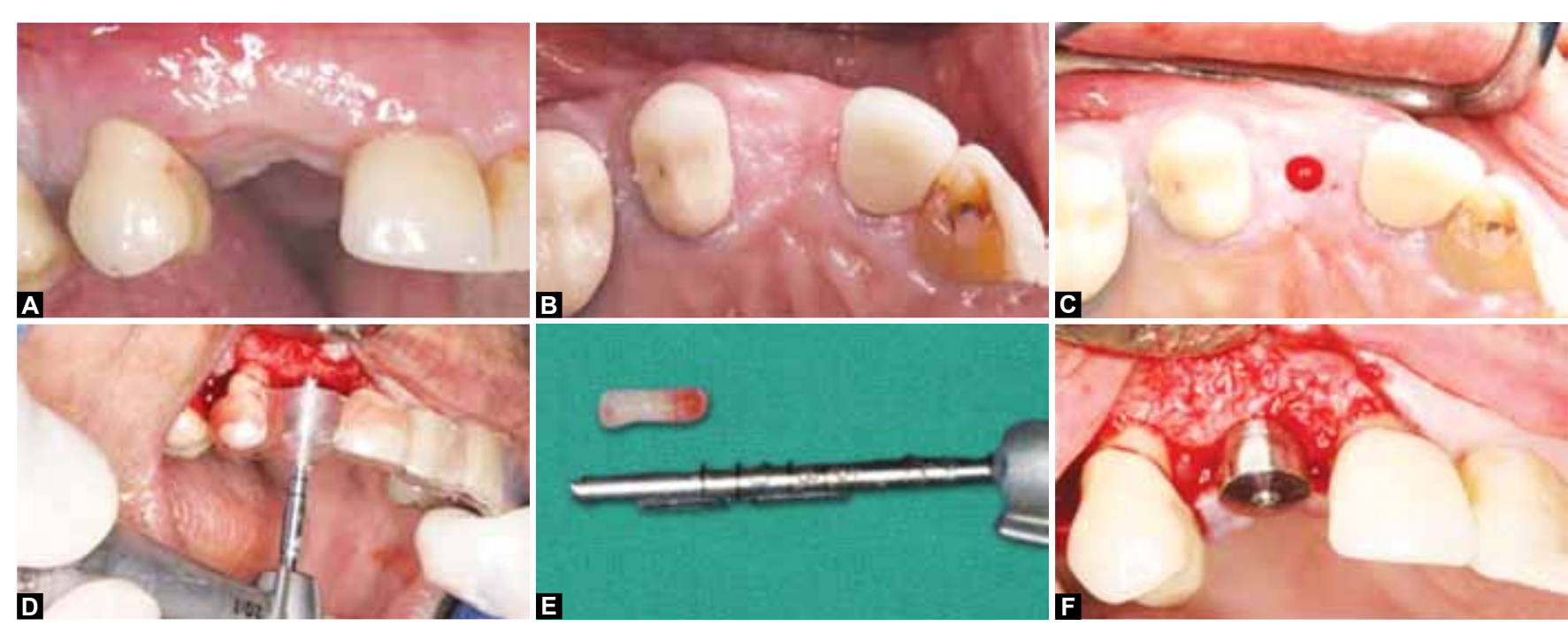

Figs 4A to F: (A) Ridge 5 months after ridge preservation (buccal view), (B) ridge 5 months after ridge preservation (occlusal view),

(C) soft tissue biopsy, (D) obtaining the bone core, (E) bone core and $(F)$ implant placed

used to determine the presence of elastin fibers which are not found in connective tissue or gingival tissue, but skin and the ADM. Elastin fibers are used as a marker for the ADM. ${ }^{12}$ If elastin fibers were not seen, it was assumed that the ADM was not incorporated and not involved in the results. However, if elastin fibers were present in the deeper areas and these areas had normal cellular components, it could be assumed that the ADM has become incorporated and participated in the healing. Typically, Verheoff's elastin stain is used for the demonstration of pathologic changes in elastic fibers, which include atrophy of the elastic tissue, thinning or loss that may result from arteriosclerotic changes, and reduplication, breaks, or splitting that may result from other vascular diseases. In addition, this stain is used to demonstrate normal elastic tissue, as in the identification of veins and arteries, and to determine whether or not the blood vessels have been invaded by tumor. ${ }^{13}$

\section{Statistical Analysis}

The data was entered into a statistical software program (SPSS, Chicago, IL, USA) for analysis. The mean values of all measurements for both groups were determined by using the individual means from each patient. Data were calculated and expressed as the mean value \pm standard deviation (SD). The significance of the differences in clinical parameters was analyzed between groups at baseline and follow-up and within each group from baseline to follow-up with the Student t-test and the 2-tailed paired t-test, respectively, $\mathrm{p} \leq 0.05$ was considered statistically significant. Inter-rater reliability between the 3 examiners was determined using the Pearson product-moment correlation test.

\section{RESULTS}

The study population consisted of 16 patients ( 8 females and 8 males). The mean patient age was similar in both groups
( 55 years for $\mathrm{ADM}$ and 50 years for $\mathrm{CT}$ ), 26 to 70 years. The 16 patients had 18 teeth that required extraction; 2 of the 16 patients needed 2 teeth extractions. The primary reason for tooth extraction was endodontic failure (14 of 18), the remaining had nonrestorable caries (4 of 18).

Prior to surgery, a stent was fabricated for each extraction site using diagnostic casts and malleable acrylic (Triad, Dentsply International, York, PA). Each stent rested on the occlusal surfaces of at least one tooth on each side of the tooth to be extracted. A computer program randomly assigned sites to either the CT group (autogenous bone + connective tissue) or the ADM group [autogenous bone + Puros ${ }^{\circledR}$ Dermis (Zimmer Dental, Carlsbad, CA)]. There were 10 sites for $\mathrm{CT}$ and eight sites for ADM.

\section{Clinical Observations}

All extraction sites healed without complications. Sixteen of the eighteen alveolar ridge sites had implants placed at the re-entry surgery At baseline, the mean buccolingual socket width was $7.99 \pm 1.32 \mathrm{~mm}$ for the CT group $v s$ $7.89 \pm 1.38 \mathrm{~mm}$ for the ADM group. While the mean mesio-distal socket width was $10.41 \pm 1.36 \mathrm{~mm}$ for the CT group vs $10.31 \pm 1.90 \mathrm{~mm}$ for the ADM group. The mean buccal plate width was $0.56 \pm 0.38 \mathrm{~mm}$ (range: 0.15 to $1.45 \mathrm{~mm}$ ) for the CT group and $0.62 \pm 0.26 \mathrm{~mm}$ (range: 0.3 to $1.0 \mathrm{~mm}$ ) for the ADM group, whereas the mean lingual plate width was $1.32 \pm 0.50 \mathrm{~mm}$ (range: 0.50 to $2.05 \mathrm{~mm}$ ) for the CT group and $1.39 \pm 0.33 \mathrm{~mm}$ (range: 1.0 to $2.0 \mathrm{~mm}$ ) for the ADM group (Table 1). There was no statistically significant difference between the two groups.

Following extraction and ridge preservation (at least 16 weeks of healing) the 18 sites proceeded with the implant. Sixteen sites had implant placement at day of re-entry. The other two sites, one CT and one ADM treated site, required 
additional guided bone regeneration procedures to increase the buccolingual ridge width in order to achieve an esthetic implant placement at a later date.

The mean buccolingual (horizontal) ridge width loss post ridge preservation was $0.19 \pm 0.99 \mathrm{~mm}$ and 0.19 $\pm 0.82 \mathrm{~mm}$, for CT and ADM group, respectively. Vertical bone gain for the CT group was: $1.26 \pm 1.92 \mathrm{~mm}(\mathrm{MB})$, $0.90 \pm 0.85 \mathrm{~mm}(\mathrm{ML}), 1.50 \pm 1.64 \mathrm{~mm}$ (DB), $0.66 \pm 0.71$ $\mathrm{mm}$ (DL). Vertical bone gain for the ADM group was $1.07 \pm$ $0.95 \mathrm{~mm}$ (MB), $0.59 \pm 1.23 \mathrm{~mm}$ (ML), $1.05 \pm 0.50 \mathrm{~mm}$ (DB), $0.55 \pm 1.20 \mathrm{~mm}$ (DL). The mean vertical (mesial and distal crest) bone gain for the CT treatment group was $1.08 \pm$ $0.37 \mathrm{~mm}$. Whereas, the mean vertical (mesial and distal crest) bone gain for the ADM group was $0.81 \pm 0.28 \mathrm{~mm}$. There was no statistically significant difference in vertical and horizontal bone gain on the ridge crest between the study groups (Table 2). Similarly, no statistically significant difference was observed between the two treatment modalities in the sites which did not receive an implant.

\section{Histological and Histomorphometric Analysis}

Histology of the soft tissue biopsies demonstrated presence of elastic fibers in all ADM samples which indicates that the ADM was still present and incorporated into the soft tissue (Figs 5A and B). Histomorphometric analysis of the osteotomy sites using a light microscope and hematoxylin and eosin stains revealed a mean $40.67 \%$ core bone fill vs $50.76 \%$ core bone fill of vital bone for $\mathrm{CT}$ and $\mathrm{ADM}$ respectively. The remaining components of the bone cores were marrow and fibrous tissue. No statistical significant difference was found between the two treatment groups (Table 3).

\section{DISCUSSION}

Alveolar bone loss at the buccal, lingual, and apical crestal area of the alveolar ridge is a well-known phenomenon. similar bone loss can also occur in periodontal disease, pathology, or trauma to teeth or alveolus. In addition, traumatic tooth extraction procedures may also result in additional bone loss. Currently, implant therapy is often considered one of the best options to replace a tooth, both functionally and esthetically. However, sufficient alveolar bone volume and favorable ridge architecture are essential to obtain favorable functional and esthetic prosthetic reconstruction following implant therapy. ${ }^{14}$

It has been suggested that an intact buccal bone plate in the maxilla and mandible must be $\geq 1.8 \mathrm{~mm}$ thick in order to preserve the buccal plate height, adequate soft tissue margin, and prevent future tissue loss. When the remaining facial plate was less than $2 \mathrm{~mm}$ after implant placement, vertical bone loss occurred at a greater frequency. The implants with greater than $3 \mathrm{~mm}$ vertical bone loss had a mean facial bone thickness of $1.3 \mathrm{~mm}$ at insertion. Thus, it is of critical importance to preserve the integrity of the buccal bone from the initial tooth extraction to the final implant restoration. After extraction, the changes that occur in the buccal bone are primarily due to the presence of bundle bone in the crestal region ${ }^{15,16}$ specifically illustrated the importance of ridge preservation by reporting less horizontal bone loss

Table 1: Baseline measurements

\begin{tabular}{llllll}
\hline & \multicolumn{5}{c}{ Site statistics } \\
\cline { 2 - 5 } & Membrane & $N$ & Mean & Std. deviation & $p$-value \\
\hline Buccal plate width $(\mathrm{mm})$ & CT & 10 & 0.563 & 0.3828 & 0.121 \\
& ADM & 8 & 0.622 & 0.2582 & 0.091 \\
Lingual plate width $(\mathrm{mm})$ & CT & 10 & 1.320 & 0.5029 & 0.159 \\
& ADM & 8 & 1.388 & 0.3335 & 0.118 \\
\hline
\end{tabular}

${ }^{*} p \leq 0.05$ statistical significant

Table 2: Treatment effect on ridge dimensions (horizontal and vertical changes)

\begin{tabular}{llllll}
\hline $\begin{array}{l}\text { Baseline measurement re-entry } \\
\text { measurement }(\mathrm{mm})\end{array}$ & Site & $N$ & Mean & SD & SEM \\
\hline Bone height (MB) & CT & 10 & -1.260 & 1.915 & 0.606 \\
& ADM & 8 & -1.069 & 0.954 & 0.337 \\
Bone height (ML) & CT & 10 & -0.900 & 0.853 & 0.270 \\
& ADM & 8 & -0.591 & 1.226 & 0.433 \\
Bone height (DB) & CT & 10 & -1.498 & 1.642 & 0.519 \\
& ADM & 8 & -1.050 & 0.496 & 0.175 \\
Bone height (DL) & CT & 10 & -0.655 & 0.713 & 0.226 \\
Buccolingual & ADM & 8 & -0.553 & 1.196 & 0.423 \\
Ridge width & CT & 10 & 0.190 & 0.986 & 0.312 \\
Mesial distal & ADM & 8 & 0.190 & 0.817 & 0.289 \\
Ridge width & CT & 10 & -0.0550 & 1.180 & 0.372 \\
\hline
\end{tabular}

Positive number: loss of bone; Negative number: gain of bone; ${ }^{*}$ The differences between the means were not statistically significantly different 

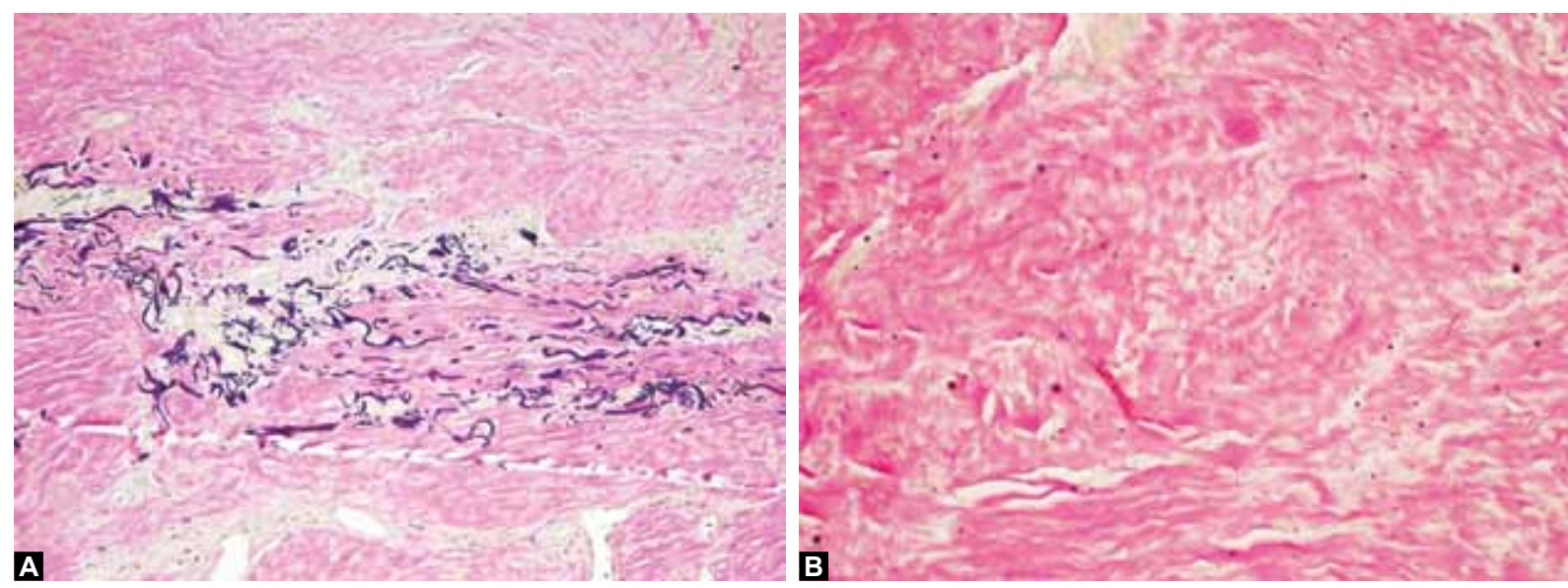

Figs 5A and B: Soft tissue biopsy: (A) presence of elastin and (B) no presence of elastin

and a gain in vertical bone in grafted extraction sockets $v s$ extraction alone. Extraction socket that did not receive bone graft had 29\%, collapse of the alveolus. While grafting the socket with tetracycline hydrated freeze-dried bone allograft and a collagen membrane at the time of extraction resulted in bone loss of only $13 \%{ }^{16}$ In this study, the mean buccolingual ridge width collapse was only $9.7 \%$ with grafting procedures, which confirms the effectiveness of the ridge preservation procedure.

There are clinicians that believe placing an immediate implant in an extraction socket, the bone around the implant will be preserved, while eliminating the ridge preservation procedure. Froum et $\mathrm{al}^{17}$ suggested that an immediate implant should be placed as much as $3 \mathrm{~mm}$ lingual to the buccal plate to make sure there is sufficient buccal bone present around and implant. The residual ridge resorbs palatally in the maxilla and lingually in the mandible, compromising the buccal cortical plate in all areas of the jaws, regardless of the site. ${ }^{18}$ In contrast, Block et a ${ }^{19}$ suggested there is no difference between the bone response around immediately placed and delayed implant placement. However, they recommended that a predictable method to control the implant buccal bone thickness is to place the implant into a healed grafted extraction socket. Covani et $\mathrm{al}^{20}$ proposed that grafting extraction sockets is the only sure method to avoid losing too much bone. In his study, implants were placed after extraction of single-rooted teeth. At the implant uncovering, measurements were obtained and they found a $35.2 \%$ loss of bone volume in the buccolingual dimension, providing evidence that immediate implant placement might not necessarily preserve facial alveolar bone as previously

Table 3: Histomorphometric analysis

\begin{tabular}{lllll}
\hline Site & $N$ & Mean & Std. deviation & $p$-value* \\
\hline CT & 10 & 0.4067 & 0.18386 & 0.150 \\
ADM & 8 & 0.5076 & 0.08872 & 0.150 \\
\hline
\end{tabular}

${ }^{*}$ The differences between the means are not statistically significantly different thought. Other studies have shown similar evidence of socket collapse after placement of immediate implants. ${ }^{21,22}$

It is a well know phenomenon that bone remodels after the extraction of teeth. However, the rate of resorption and total bone loss that occurs varies from individual to individual due to anatomic, metabolic and functional factors. As a result, numerous clinical studies are devised to find a predictable treatment method of maintaining or augmenting the bone that is already present. Dimensional changes after tooth extraction can severely complicate restorations with implant and traditional fixed or removable prosthesis. In addition, these changes can lengthen treatment by several months, causing more physical stress on the patient, as well as a strain financially. This study is one of many studies attempting to find a more predictable method to successfully restore an edentulous ridge esthetically and functionally.

The results of this study illustrate that ridge preservation with CT or ADM is a procedure that can be used predictably. The study warrants further investigation with a larger sample size to verify the value of ridge preservation. In order to lessen the considerable patient variability within this study, sites should be limited to an equal number of maxillary and mandibular sites since bone resorption occurs at different rates in the maxilla and the mandible.

\section{CONCLUSION}

Both membranes, connective tissue and acellular dermal matrix, were useful barriers. This study supports that ridge preservation using CT or ADM with autogenous bone reduced bone loss and helped maintain adequate alveolar bone for implant prostheis.

\section{REFERENCES}

1. Darby I, Chen S, De Poi R. Ridge preservation: what is it and when should it be considered. Aust Dent J 2008;53:11-21.

2. Buser D, Dula K, Hess D, Hirt HP, Belser UC. Localized ridge augmentation with autografts and barrier membranes. Periodontol 2000-1999;19:151-163. 
3. Wang HL, Kiyonobu K, Neiva RF. Socket augmentation: rationale and technique. Implant Dent 2004;13:286-296.

4. Rose L, Mealey B, et al. Periodontics: medicine, surgery and implants. Elsevier Mosby 2004.

5. Becker W, Dahlin C, et al. The use of e-PTFE barrier membranes for bone promotion around titanium implants placed into extraction sockets: a prospective multicenter study. International Journal of Oral and Maxillofacial Implants 1994;9(1):31-40.

6. Sclar AG. Strategies for management of single-tooth extraction sites in aesthetic implant therapy. Journal of Oral and Maxillofacial Surgery 2004;62(9 Suppl 2):90-105.

7. Novaes AB Jr, RR de Barros. Acellular dermal matrix allograft. The results of controlled randomized clinical studies. J Int Acad Periodontol 2008;10(4):123-129.

8. Wong AK, Schonmeyr B, et al. Histologic analysis of angiogenesis and lymphangiogenesis in acellular human dermis. Plastic and Reconstructive Surgery 2008;121(4):1144-1152.

9. Hinton R, Jinnah RH, et al. A biomechanical analysis of solventdehydrated and freeze-dried human fascia lata allografts. A preliminary report. American Journal of Sports Medicine 1992;20(5):607-612.

10. Moreau MF, Gallois Y, et al. Gamma irradiation of human bone allografts alters medullary lipids and releases toxic compounds for osteoblast-like cells. Biomaterials 2000;21(4):369-376.

11. Sclafani AP, McCormick SA, et al. Biophysical and microscopic analysis of homologous dermal and fascial materials for facial aesthetic and reconstructive uses. Arch Facial Plast Surg 2002;4(3):164-171.

12. Harris RJ. Root coverage with a connective tissue with partial thickness double pedicle graft and an acellular dermal matrix graft: a clinical and histological evaluation of a case report. Journal of Periodontology 1998;69(11):1305-1311.
13. Mallory, Sheehan, et al (eds). Histotechnology: a self-instructional text Chicago. ASCP Press 1990.

14. Schropp L, Wenzel A, et al. Bone healing and soft tissue contour changes following single-tooth extraction: a clinical and radiographic 12-month prospective study. International Journal of Periodontics and Restorative Dentistry 2003;23(4):313-323.

15. Araujo MG, Lindhe J. Ridge preservation with the use of biooss collagen: a 6-month study in the dog. Clinical Oral Implants Research 2009;20(5):433-440.

16. Iasella JM, Greenwell H, et al. Ridge preservation with freezedried bone allograft and a collagen membrane compared to extraction alone for implant site development: a clinical and histologic study in humans. Journal of Periodontology 2003;74(7):990-999.

17. Froum SJ, Cho SC, et al. Immediate implant placement and provisionalization-two case reports. Pract Proced Aesthet Dent 2007;19(10):621-628; quiz 630.

18. Pietrokovski J. The bony residual ridge in man. J Prosthet Dent 1975;34:456-462.

19. Block MS, Mercante DE, et al. Prospective evaluation of immediate and delayed provisional single tooth restorations. Journal of Oral and Maxillofacial Surgery 2009;67(11 Suppl): 89-107.

20. Covani U, Cornelini R, et al. Bucco-lingual bone remodeling around implants placed into immediate extraction sockets: a case series. Journal of Periodontology 2003;74(2):268-273.

21. Botticelli D, T Berglundh, et al. Hard-tissue alterations following immediate implant placement in extraction sites. Journal of Clinical Periodontology 2004;31(10):820-828.

22. Araujo MG, Wennstrom JL, et al. Modeling of the buccal and lingual bone walls of fresh extraction sites following implant installation. Clinical Oral Implants Research 2006;17(6):606-614. 